\title{
The EU Stabilisation and Association Agreement for the Western Balkans: Between Challenges and Opportunities
}

Gazmend Qorraj, Gezim Jusufi

\section{Abstract}

The role of the European Union (EU) trade liberalisation with the four Western Balkan countresnamely Kosovo, Montenegro, Albania, and Macedonia - is overestimated, as major benefits could be expected mainly from institutional reforms rather than trade creation and economic perspective due to low economic development and a lack of comparative advantages in these countries ${ }^{l}$. The core issue to be addressed in this article is whether these firms can exploit the opportunities arising from the EU integration process. The aim of this article is to confirm the hypothesis that the Stabilization and Association Agreement (SAA) and trade agreements in the Western Balkans are not sufficient pre-conditions for successful performance and increase of exports by local firms; the main focus should be on the internal performance of firms. The paper analyses and compares the data collected by surveys conducted with local firms in Kosovo in order to measure the impact of the SAA. Finally, the article suggests that in the short and medium run the SAA could support and improve the quality of products, technical standards, and firm competitiveness as a pre-condition for better access to the EU market in the long run.

\section{KEY WORDS:}

SAA, EU integration process, local firms, growth, free trade, export 


\section{Introduction}

Within the framework of the European integration process, the EU tends to create a better environment for the market integration of Kosovo, leading to increased export capabilities, accelerated institutional reforms, and economic convergence ${ }^{2}$. A number of authors have argued that trade integration will support firm opportunities; therefore, European integration will have a positive impact for old member states but also for candidate countries (Mayhew 1999: 27; Knaack and Jager 2003). Smallbone and Rogut (2003: 54) have concluded that the main opportunities from market integration are new export opportunities in the EU market, achieving economies of scale by employing EU standards, abolishment of trade obstacles, and ensured free trade. Despite the positive effects, the authors also considered the negative impacts, such as increased competition in domestic markets and increased costs due to harmonisation of technical standards. Taking these factors into consideration, the question is whether market integration for the Western Balkans (WB) as an external variable is a sufficient condition for local firms to enter the EU market and exploit these opportunities. Furthermore, Smallbone and Rogut (2003: 54) extended the analysis with the fact that the EU market tends to favour large firms compared to local small firms, which is an additional challenge for the WB taking into consideration the large number of small firms in the region.

In this article, compared to other studies that analyse exporting trends, we instead analyse from a microeconomic perspective using two types of firms in Kosovo: exporting and non-exporting firms. In order to empirically support our analysis, we employed two types of questionnaires, one for exporting firms and one for non-exporting firms. The aim of separating the firms into two groups was to measure the support of the SAA for exporting trends and to analyse the barriers that prevent the second group of firms from exporting at the EU market.

By using statistical packages and obtaining descriptive statistics, the survey enables us to analyse the main factors affecting these firms in accessing the EU market, considering the challenges and specific business

2 The SAA is a mechanism of the EU integration framework that was created in 1999 and advanced in 2003 by including the EU integration components. 
environment in the WB. The survey also will identify why the second group of firms cannot export abroad and thus take advantage of the opportunities through the SAA.

\section{Methodology}

According to Aidis (2003), there is a lack of sufficient and accurate data for the firms in transition countries. Ensuring data for these firms is a complex issue. Usually, large number of firms created during the 1990s were not functioning in the market therefore they closed their activity, but these firms were still listed on the Business Registration Authority. Furthermore, Mclntyre and Dallago (2003: 1-17) added that the creation of firms is reported, while firm failures are not registered. In this paper, we first perform a literature review to gather data on recent academic and professional papers published by different authors.

Due to a lack of data available on small and medium-sized enterprises (SMEs) in Kosovo, we conducted individual surveys with local firms in Kosovo. The analysis consists of two stages. In the first stage, we selected data for the firms from the Kosovo Customs Authority, but only firms that are exporting abroad; therefore, this was a limitation, as there are not many firms in Kosovo that are exporting abroad. Thus, we could not select firms based on any specific sector. With regard to the regional dimension, we surveyed firms in Prishtina and Gjilani. The second group of firms was selected regionally based in Prishtina and Gjilani as the main cities in Kosovo.

The main approach of this selection was to choose entrepreneurs with better knowledge of the SAA in order to ensure a high rate of response as well as appropriate answers. While compiling the surveys, the aim was to design simple questionnaires and avoid complex questions, such as personal questions and questions related to financial and tax issues in order to address the main questions of the article. Therefore, due to the small number of questions and the academic purpose of the surveys, the 
response rate was almost $100 \%$ for both questionnaires and individual questions.

In the second stage, we conducted surveys with the selected firms from the customs authority or "exporters" and the second group of firms or "non-exporters." We employed a survey of 100 local firms exporting to EU countries as well as 100 local firms operating mainly in the local market. This was done in order to evaluate and measure if the increase of exports is due to the SAA or mainly internal factors of the firms. The surveys were conducted in the period from April to May 2017, as April 2017 marked one year since the SAA implementation in Kosovo. Our paper is also supported by comparing exporting trends of Kosovo firms after SAA implementation based on data from the Kosovo Statistical Agency. The additional comparison was performed by analysing the World Bank Report of 2017. The main limitations of this article are the short period of the SAA implementation in Kosovo and the small sample of the entrepreneurs selected for the survey.

\section{Theoretical background}

In this section, we briefly review the main trade theories of different authors with regard to trade liberalization, trade creation, diversion, partial integration, global trade concepts, and intra- and inter-trade industry. During the 1950s, trade liberalisation or free trade between countries was generally accepted as a positive concept by the majority of authors with many benefits, such as reduction of tariffs and quotas as well as elimination of other trade restrictions based on increased economic welfare.

From another point of view, authors such as Jacob Viner (1950: 49), studying trade effects, reported contradictory effects of trade liberalisation, known as "trade diversion effects" are a case in which policy discrimination does not allow low-cost producers from outside of the customs union to enter the market freely despite the higher cost of the partner country's producers. In contrast "trade creation," is accepted as positive concept 
in which a high-cost producer is replaced by a low-cost producer of the partner country.

By analysing from the perspective of a small group of countries and taking into consideration a global approach and the impact on all countries, Viner accepted the liberalisation of trade as a "discriminatory liberalisation." Furthermore, Lipsey (1957: 14) continued with the analysis of trade not only from the production approach but also from the consumption perspective. The trade analysis was further extended with the so-called regional free trade known as "partial integration" between specific groups of countries, which is considered that increases the region's terms of trade at the rest of world's expense respectively reduce the world efficiency and create negative effects for the third countries which are not part of a specific customs union (Krugman 1990: 11). On the contrary, global free trade was seen as the "first best solution," which could maximize economic welfare globally and minimise monopoly positions and negative spillover effects. In addition, it is important to also reflect on the global customs union and which type of union could replace the idea for global free trade. The global customs union will impose similar trade rules for all countries and reduce the negative effects from trading blocks.

Another crucial component of regional integration is inter-industry trade and intra-industry trade, firstly launched by countries of the European Economic Community (EEC) (Hadjinski et al. 2010: 5-7). Specifically, intra-industry trade is crucial for economic growth, as this type of trade means trade of products between similar industries or similar products. Why is this important for economic growth? This type of trade accelerates innovative ideas and innovation trends as well as a large variety of the products supported by economies of scale and competition. In contrast, inter-industry trade is based on trade between different products and different industries supported by comparative advantages of the different countries. Finally, the majority of authors accept that besides the benefits and costs of the different types of market integration, crucial issues for countries are also the structure of their market, identification of comparative advantages, as well as the innovation level of firms in these countries. 


\section{A Trade relations and the SAA in the Western Balkans}

The violent history of the region during the 1990s and the prolonged transition to market reforms had a negative effect on trade integration. A global financial crisis resulted in prolonged economic slowdown in the WB and had a toll on exports during the last decade. This translated into fewer exports compared to other emerging markets in Central and Eastern Europe, although in 2000 the EU granted autonomous trade concessions to the WB countries. This measure was introduced to support them for around $95 \%$ of their exports to enter the Union free of duties and any quantitative limits ${ }^{3}$. Furthermore, in 2007 these countries joined the Central European Free Trade Agreement (CEFTA 2006).

WB countries have some comparative advantages for a range of their products and services that could penetrate EU markets and beyond. However, they still need to improve their productivity by investing in skills and new technology and to accelerate their exports by introducing new products and following external market trends. The recent trade data suggest that some WB countries expanded their market shares in the EU, of which Serbia and Bosnia and Herzegovina benefited the most due to their larger production base, followed by Macedonia, whereas the other three countries lagged behind. Yet, despite recent expansion of exports, the WB countries remain poorly integrated into EU market.

Some countries are better integrated in the trade channels than others, as measured by a higher share of exports in their gross domestic product (GDP). The main exporting countries from the region are Serbia, Macedonia, and Montenegro, with goods and services exports account for roughly $40 \%$ of GDP, followed by Albania and Bosnia and Herzegovina with over $30 \%$ share; Kosovo is the last with only $19 \%$ share in GDP. Their peers, such as Slovenia, Estonia, Slovakia, and Lithuania, have much larger shares of exports, often exceeding 80\% of GDP (World Bank 2017: 5-16).

Now we analyse the impact of the SAA on the capability of Kosovo firms to gain access to the EU market. Although there is a limited period of time,

3 Products originating in the WB countries benefit since 2000 from autonomous trade measures. 
Kosovo has only one year of experience with the SAA implementation. The situation of other WB countries will be reported briefly, as these countries experienced the SAA for a longer period.

Kosovo's trade imbalances still pose a significant challenge to sustainable economic development. Since 1999 the Kosovo market has been flooded by imports, while exports have been negligible. Kosovo made some progress in improving its business climate to support export-related business activity, but it remains at an underdeveloped stage of market economy, and businesses face numerous constraints in their daily activity. Among those constraints, one should mention trade restrictiveness, weak contract enforcement (especially within the financial sector), and access to finance. The persistent trade deficit and current account deficit reflect a weak production base and poor international competitiveness (European Commission 2016: 5-13). Over $90 \%$ of firms in the private sector in Kosovo are either small or micro firms, making the SME sector dominant and very important to promote growth. As such, it is the main employer, accounting for about $80.7 \%$ of overall formal employment in 2013 , where micro firms (2-9 employees) employed $31.9 \%$ as of the same year. This is well above the European average of $67 \%$ for the same year. The number of SMEs in Kosovo grew steadily over the past several years, according to the official business registry statistics, with about 10,000 new enterprises registered on an annual basis between 2012 and 2015. However, the largest share of this growth is attributed to the registration of previously unregistered enterprises (going formal), as the informal sector is estimated to be high at around $30 \%$, and many of them are registered as sole proprietorships. Based on 2014 data published by the Kosovo Agency of Statistics, the majority of Kosovo's firms are wholesale and retail trade companies. This is in line with the popularity of trade activities among small proprietors and is supported by the fact that $37.3 \%$ of employment is provided by the trade sector. Manufacturing, on the other hand, accounts for $12.7 \%$ of the enterprises and $15.3 \%$ of employment, suggesting that these companies have a larger number of employees per company 'European Investment Bank 2016: 11-12). The main destination for Kosovo's exports in 2017 was the CEFTA with $48.3 \%$ of overall export of goods, followed by the EU market with $24.9 \%$, other European non-EU markets with $7.7 \%$, and the rest of the world with $19 \%$. The main destination in EU was Germany with $21.4 \%$ share in exports to the EU, followed by the Netherlands with $13.5 \%$ and Austria 
with $11.2 \%$, with all three growing in the last year. The main destinations in the CEFTA are Albania with $33 \%$, Serbia with $26.2 \%$, Macedonia with $25.1 \%$, Montenegro with $10.9 \%$, and Bosnia and Herzegovina with $4.8 \%$ of exports to the CEFTA.

From another point of view, most firms in the WB are not exporters, choosing instead the domestic market as the destination of their products. The majority of Albanian firms (about $87 \%$ ) are oriented towards the local market, $10 \%$ of overall firms export to the EU market, and only the remaining $3 \%$ sell to other WB countries. The exporting companies in all countries of the WB region are linked more with the EU market than with the other regional neighbours. Serbia and Kosovo are the only two countries with larger exports to the region compared to their exports to the EU market. Kosovo is also the main importer of Serbian exports to the region. In this article, it is important to also address the reforms undertaken by Kosovo's institutions towards elimination of trade barriers and other costs for the firms identified by the Doing Business Report (2018) of the World Bank. According to this report, Kosovo is among the 10 economies worldwide that have undertaken significant reforms during 2016 and 2017 compared to previous years. Furthermore, the report explains three main areas in which Kosovo performed deep reforms: simplifying business registration procedures, simplifying credit procedures, and simplifying insolvency procedures (World Bank Group 2017: 5-16).

According to other areas, there is no significant change from past years. Despite the internal challenges of firms, there are obstacles to firms in Kosovo with regard to the business environment, such as costly financing and short-term loan maturity for the firms, improving and sharing credit information, strengthening investor protection, standardising the taxing system, trade across borders, and enforcement of contracts. An additional challenge for firms in Kosovo compared to the region is in relation to the free movement of business people, as Kosovo is still facing barriers to move to EU countries due to visa liberalisation. This is among the main obstacles for networking and partnership with EU firms and, consequently, increases the transaction costs of local firms.

Regarding the SAA effects in the other WB countries, we now briefly describe the impact of the SAA on Macedonia, Montenegro, and Albania. 
Macedonia was the first regional state to sign the SAA. The implementation of the SAA is estimated to have contributed to the acceleration of Macedonia's economic development and its industrial and agricultural production, as well as the increasingly important service delivery (Secretariat for European Affairs [SEA] of Macedonia 2011 : 10). According to the State Statistical Office of Macedonia (2014: 1), immediately after SAA came into force, Macedonia's exports to the EU began to increase gradually. On the contrary, according to Tosevska (2007: 10), despite having the SAA, Macedonia is experiencing a continuous trade deficit due to a lack of competitiveness in the EU market.

Montenegro adopted the SAA in March 2007. Montenegro recently has also advanced in pursuing fiscal consolidation and improving the business environment. Its trade is also characterised by a smaller amount of imports compared with other regional countries, imports which were gradually deducted after the adoption of the SAA. After the SAA implementation, exports to the EU doubled (Montenegro Statistical Office 2015: 4).

Albania started implementing its SAA with the EU in April 2009. It has made some progress in improving the functioning of the market economy. During 2009-2013, Albanian firms increased their volume of exports to the EU market, while in 2011 there was an increase in imports also. Furthermore, in 2013 exports in the EU market accounted for $76.7 \%$ of total exports. This accounted for an increase of $17.3 \%$, while the volume of imports from the EU market for 2013 accounted for $64.3 \%$ of total imports and decreased by $0.4 \%$ compared to 2012 (INSTAT 2014: 6). Finally, due to a lack of firm competitiveness, there is a permanent account deficit and thus low economic development in Albania (European Commission 2014: 3).

\section{Results}

The following section of the article presents the descriptive statistics derived from the analysis. The main results from the survey conducted with the local firms are as follows: first, we analysed the firms exporting in the EU 
market; therefore, the managers of these firms declared that they are well informed about the SAA ${ }^{4}$. Most of them, around $66.7 \%$, are informed from local institutions such as the Ministry of Trade and Industry, while $28.6 \%$ are informed by the local media. Also, $86 \%$ of managers have a positive opinion about the SAA; only $14 \%$ have a neutral opinion.

Regarding expectations from the agreement, most managers declared economic aspects to be important, compared to $19 \%$ who declared that reducing informality in the economy was important. In order to check if the firms benefited from the SAA, we asked if they were exporting before the implementation of the SAA or after it; $86 \%$ of managers declared that they were already exporting to the EU market, while only $14 \%$ started exporting after the SAA implementation.

\section{Table 1: Main factors supporting firms to export to the EU market}

\begin{tabular}{|l|c|}
\hline Supporting Factors for Exporting Firms & $\%$ \\
\hline SAA & $10 \%$ \\
\hline Government policies & $19 \%$ \\
\hline Production capabilities & $38 \%$ \\
\hline Partnership with EU firms & $29 \%$ \\
\hline
\end{tabular}

Source: Authors

Regarding the question about the main factors that supported firms to export to the EU market, only $10 \%$ of managers declared due to the SAA, $19 \%$ due to government policies, $38 \%$ due to production capabilities, and $29 \%$ due to partnership with EU firms, as described in Table 1.

Furthermore, it was important to analyse the main factors that should improve in the future in order to optimally use the EU market ${ }^{5}$. Around $20 \%$ of respondents declared that human resources are among the main factors, while $24 \%$ believe them to be government policies, only $15 \%$ rely on production capabilities, and most, around 39\%, chose EU financial

4 The results from the survey were obtained using the statistical package STATA and are mainly descriptive statistics.

5 The questionnaire was designed not only to analyze the supporting factors for exporting firms but also to obtain additional information about the level of knowledge of firms about the SAA. In addition, we also surveyed the future needs of the firms. 
support for their SME-s. Regarding future needs towards EU and local institutions, around $15 \%$ of respondents declared exchange of experiences as a need, $15 \%$ chose economic cooperation, $24 \%$ believe that tax-free packages from the government for the firms that export to the EU market are needed, and around $46 \%$ think that EU grants are needed for this purpose.

We will continue to explain the findings from the non-exporting firms in order to analyse the difference between exporting and non-exporting firms ${ }^{6}$. Regarding the information about the SAA, around $78 \%$ of respondents declared to have been informed, while $22 \%$ declared that they do not have information about the SAA. Of the informed respondents, $66 \%$ were informed from the Ministry of Trade, while around $34 \%$ were informed by the media $^{7}$. Regarding expectations of the SAA process, around $25 \%$ are neutral, $15 \%$ have negative expectations, and $60 \%$ have positive expectations. Among the respondents with a positive approach, $70 \%$ believe that the SAA has a positive impact on economic reforms, while $30 \%$ believe it reduces informality.

Since these firms did not export to the EU market, we analysed the main obstacles. Around $34 \%$ of the firms declared that production capabilities are the main problem, $20 \%$ rank government policies as the main problem, $24 \%$ stated the partnership with EU firms, $10 \%$ stated financial support, and $12 \%$ stated a lack of human resources and professionals with technological background. As a pre-condition to exporting to the EU market, most firms, or $40 \%$ of them, focused on increasing production capacities, followed by government policies at $23 \%$, EU financial assistance for the SME-s around $15 \%$, and human resources at $22 \%$. These factors are described below in Table 2.

6 The questionnaire for non-exporting firms was performed to analyze the barriers preventing these firms from entering the EU market. Also, there is a crucial need to analyze the difference between non-exporting firms compared to exporting firms. From the data, we can see that exporting firms have higher positive opinions about the SAA compared to non-exporting firms.

7 The data in Tables 2 and 3 represent only the current state of firms in Kosovo with regard to opportunities from the SAA. The data for other WB countries will be used from other sources such as World Bank Reports. 
Table 2: Main barriers for firms to export to the EU market

\begin{tabular}{|l|l|}
\hline Barriers for Non-Exporting Firms & $\%$ \\
\hline Financial support & $10 \%$ \\
\hline Government policies & $20 \%$ \\
\hline Production capabilities & $34 \%$ \\
\hline Partnership with EU firms & $24 \%$ \\
\hline Human resources ( technical staff) & $12 \%$ \\
\hline
\end{tabular}

Source: Authors

In order to extend the analysis, we used the latest report of the World Bank in the table below, including data from 2013 to 2017, thus showing the challenges of these countries to increase their exports. Except for Serbia, the countries of the region experienced relatively small changes of less than $0.5 \%$ of GDP in their current account deficits.

Table 3: Goods exports from WB (\% of GDP)

\begin{tabular}{|l|c|c|c|c|c|}
\hline WB6 Countries & $\mathbf{2 0 1 3}$ & $\mathbf{2 0 1 4}$ & $\mathbf{2 0 1 5}$ & $\mathbf{2 0 1 6}$ & $\mathbf{2 0 1 7}$ \\
\hline Albania & 10.9 & 9.3 & 7.5 & 6.7 & 6.6 \\
\hline $\begin{array}{l}\text { Bosnia and } \\
\text { Herzegovina }\end{array}$ & 24.8 & 25.1 & 25.2 & 25.7 & 25.6 \\
\hline Kosovo & 5.5 & 5.9 & 5.6 & 5.1 & 5.7 \\
\hline Macedonia & 29.2 & 33.5 & 33.6 & 35.2 & 37.7 \\
\hline Montenegro & 11.8 & 10.3 & 8.9 & 8.7 & 8.4 \\
\hline Serbia & 30.7 & 31.9 & 33.9 & 37.0 & 39.3 \\
\hline WB6 & 24.0 & 24.7 & 25.2 & 26.7 & 28.0 \\
\hline
\end{tabular}

Source: World Bank (2017)

According to the World Bank (2017), the results are as follows: Macedonia increased the volume of goods exported compared to imports, which

8 World Bank estimations measured by obtaining data from local institutions of the WB countries and World Economic Outlook (2017) 
decreased the trade deficit in 2017. In Montenegro, despite tourism opportunities, the volume of exports is still at a low level, while raw materials used for the Bar-Boljare highway are permanently increasing the volume of imports. In Albania, despite increasing the volume of exports, supported by the tourism sector, there is still an unstable trade balance caused by higher energy-related imports and other institutional challenges. Compared to Montenegro, Macedonia, and Albania, the worse situation is in Kosovo due to higher non-equilibrium between imports and exports? Additional challenges for Kosovo are the structure of the exports, which is not favourable, since the main source of exports is metal bases, which could be considered natural resources, as well as fewer exports based on sustainable production capabilities.

According to the tables above and the explained results, the SAA impact is relatively different in the different countries, although most of the WB countries had higher economic expectations. From another point of view, it is not easy to measure exactly the SAA effects, as the business environment in the WB countries was supported also from the reforms undertaken by the World Bank and other stakeholders within the Doing Business Report framework and other instruments.

Despite the many challenges for these countries, authors such as Kaminski and De la Rocha (2003: 61) have added that the SAA process offers unique opportunities to the WB countries to reform local institutions in line with EU requirements in order to increase institutional efficiency as well as increase the opportunities of benefiting from the EU. Therefore, the SAA framework offers good opportunity to continue integration with the EU. The deepening market integration in the WB will increase the export opportunities and, consequently, market performance, which could lead to trade benefits due to restrictive EU rules of origin and EU MFN tariffs on industrial products. However, deepening market integration depends not only on the WB objectives but also implementation of their structural reforms, as well as the support of EU institutions to continue the European integration process in the region.

9 Table 3 describes the volume of the exports and imports in the WB as a share of GDP, which is around $30 \%$, while in the new EU accession countries it reaches about $80 \%$. 


\section{ค Conclusion}

Despite the opportunities created by the European Union for the WB, there are threats from the open market, especially for small firms. Previous evidence for Central European countries suggests that small firms are not in the best competitive position with regard to the EU market, taking into consideration their limited capabilities, such as higher transaction costs, adaption costs, low level of technology, and low level of cooperation with other EU firms. A similar experience is shared by the WB, specifically Kosovo, taking into consideration additional challenges, such as political disputes with the countries of the region, delay in the SAA implementation, inadequate government policies, production capabilities, financial support as well as human resources, and lack of specialized management.

There is a limitation to this article, as there was only one year since the SAA implementation in Kosovo; therefore, it is very difficult to predict its benefits and costs. Although evidence from our analysis suggests that the SAA framework is an opportunity for firms to access the EU market, due to elimination of trade barriers and other obstacles to trade. In contrary the SAA framework is not a sufficient factor for the firms compared to other internal factors such as firm production capabilities, partnership with EU firms, as well as the introduction of government policies.

From another point of view, the non-exporting firms also declared that the main challenges for the local firms are the lack of financial support, followed by inadequate technical staff, un-sustainable government policies for the local producers, and a lack of partnerships with EU firms. The main conclusion of this article is that the SAA framework in the short run could support local firms and countries to accelerate reforms and improve technical conditions according to EU standards in order to make them capable of accessing the EU market but only in the long run. On the contrary, the pessimistic scenario is that in the short and medium period there will be even more challenges for the local firms due to competitive pressure in local market from European firms. There is intention of the firms, mainly from the new EU member countries to access at the Western Balkans market as these firms have more probability to export to the WB countries market compared to the EU market, where the competition is 
higher due to the higher demand for the qualitative products and services.

The main suggestions of this article for the WB countries are as follows: Kosovo should identify its comparative advantages, increase the competition capabilities of local firms, improve the business environment, and use EU financial assistance more effectively to compete regionally and in the EU market. In addition to economic challenges, the political disputes and political instability in the Balkans have hampered the regional economic cooperation as well as foreign direct investments, outsourcing, and other private initiatives from large firms and companies worldwide.

Albania should increase its competition capabilities in the medium period by continuing with institutional and sectorial reforms. Furthermore, Albania must improve its education system, increase the competitive potential of firms, and improve tax administration and collection (IMF 2016: 20-25).

In order to increase the benefits from the SAA, Montenegro should continue with fiscal reform packages, strengthen tax revenues, and improve the business environment by using tourism opportunities.

Macedonia should work continuously on adapting monetary and fiscal packages and prioritising public investments as well as overcome the political instability, which has led to business uncertainty (World Bank 2017: 55-69).

Finally, taking into consideration the fact that countries respectively firms in the WB did not realised the expected results from trade liberalisation, therefore in order to increase the benefits from trade, the market liberalization should be accompanied with the improvement of the technical standards in production, increase of production quality, better education of managers and offering the creative products and services at EU market. 


\section{B Bibliography}

Aidis, R., 2003. Entrepreneurship and economic transition. Amsterdam: Tinbergen Institute.

Discussion paper. Available at: http://www.tinbergen.nl [Accessed August 2017].

European Commission, 2014. Albania progress report, Brussels: 3.

European Commission, 2016. Kosovo*Report. Brussels: 5-13.

European Investment Bank, 2016. Assessment of financing needs of SMEs in the Western Balkans countries, Country report: Kosovo: 11-12.

Handjiski, B., Lucas, R., Martin, P. and Guerin, S.S. 2010. Enhancing regional trade integration in Southeast Europe, the World Bank Working Paper no. 185: 5-7.

Holzner, M. and Ivanic, V., 2012. Effects of Serbian Accession to the European Union. Panoeconomicus, 3: 355-358.

International Monetary Fund, 2016. Potential growth and output in Albania, Washington, D.C: 20-25.

Institute of Statistics of Albania, (INSTAT) 2014. Foreign trade: 6.

Kaminski, B. and De La Rocha, M., 2003. Policy-induced integration in Balkans: Policy options and their assessment*. Document of the World Bank, 24460: 61.

Kosovo Agency of Statistics (KAS), 2016. Statistical yearbook of the Republic of Kosovo: 137.

Knaack, R. and Jager, H., 2003. The costs and benefits of EU accession. Working paper, University of Amsterdam. Available at: http://www. fee.uva.nl [Accessed August 2017].

Krugman, P., 1990. The Move toward Free Trade Zones. Cambridge: MIT Press: 11.

Lipsey, R., 1957. The Theory of Customs Union: Trade Diversion and Welfare, Economica, 24: 40-46. 
Mayhew, A., 1999. Recreating Europe: The European Union's Policy towards Central and Eastern Europe. New York: Cambridge University Press: 27. McIntyre, R. and Dallago B., 2003. Small Enterprises in Transition Economies: Causal Puzzles and Policy-Relevant Research. Hampshire, UK: Palgrave: 1-17.

Michalopoulo, C., 2003. The Western Balkans in world trade. Trade policies and institutions in the countries of South Eastern Europe in the EU Stabilization and Association Process -Regional Report, 24460: 17.

Montenegro Statistical Office, 2015. Mirror Analysis Summary Report: International Trade in Goods Statistics: Statistical Report, 1: 4.

Qorraj, G. and Jusufi, G., 2017a. Survey conducted with 100 firms exporting at EU and other countries abroad. Main factors supported firms to export at EU market. Republic of Kosovo.

Qorraj, G. and Jusufi, G., 2017b. Survey conducted with 100 firms nonexporters at EU and other countries abroad. Main barriers for firms to export at EU market. Republic of Kosovo.

Secretariat for European Affairs (SEA) of Macedonia, 2011. Ten years of the enactment of the Stabilization and Association Agreement, 1: 15.

Smallbone, D. and Rogut, A., 2003. From transition to accession: The challenge for SMEs in candidate countries. Paper presented at the Research in Entrepreneurship and Small Business (RENT XVII) conference, Lodz, Poland: 54 .

State Statistical Office of Republic of Macedonia, 2014. External trade of the Republic of Macedonia: 1.

Tosevska, K., 2007. Analysis of the effects of the Stabilization and Association Agreement over the external trade of the Republic of Macedonia: International Trade and Finance Association, US, working paper: 10.

Viner, J., 1950. The Customs Union Issue. Carnegie Endowment for the International Peace, New York: 49.

World Bank, 2017. Western Balkans regular economic report: Key economic indicators, 12: 55-69.

World Bank Group, 2017. Western Balkans: Regional economic integration issues: 5-16. 
( Gazmend Qorraj (gazmendqorraj@yahoo.com) is an Associate Professor at the Faculty of Economics, University of Prishtina. He received his PhD from the University of Ljubljana in 2009 and an MA in the economics of international trade and European integration in 2004 from Staffordshire University, UK, \& Vrije University, Brussels. Since 2001, he has taught at the University of Prishtina. Since 2015, he is the national contact point for the Marie Curie Actions and European Research Council at HORIZON 2020.

Gëzim Jusufi (gezimi.gjilan@gmail.com ) is a PhD candidate in economics at the University of Prishtina. He received an MA in marketing in 2011 from the University of Prishtina, and a diploma in business administration in 2009 from Trakya University, Turkey. 